\title{
Chemical Stratification of the Mantle
}

\author{
DON L. ANDERSON \\ Seismological Laboratory, Division of Geological and Planetary Sciences, California Institute of Technology \\ Pasadena, California 91125
}

\begin{abstract}
Differentiation of the mantle results in a thick layer of basalt which cannot sink below about $670 \mathrm{~km}$ even after it converts to eclogite and gametite. The mantle is therefore chemically stratified. The upper mantle stratification is possibly garnet peridotite overlying eclogite.
\end{abstract}

The arguments for whole mantle convection seem to be based primarily on the relative uniformity of viscosity and mean atomic weight throughout the mantle [Davies, 1977; Elsasser et al., 1979], conditions which are neither necessary nor sufficient. The mean atomic weight is a parameter in the relationship between seismic velocity and density and is a function primarily of the $\mathrm{FeO}$ content. It is not a measure of density per se, and it does not play the major role in establishing the density of a given collection of oxides. $\mathrm{Al}_{2} \mathrm{O}_{3}$ and $\mathrm{SiO}_{2}$, both of which have nearly the same mean atomic weight, have a large effect on densities, since they determine the crystal structures and stability fields of silicates. $\mathrm{Al}_{2} \mathrm{O}_{3}$ stabilizes the garnet structure, making garnet-bearing aluminous assemblages denser than $\mathrm{Al}_{2} \mathrm{O}_{3}$-poor materials at moderate pressures but less dense at high pressures. Likewise, $\mathrm{SiO}_{2}$ decreases the density of low-pressure assemblages but increases density in high-pressure phases. $\mathrm{SiO}_{2}$ and $\mathrm{Al}_{2} \mathrm{O}_{3}$ are enriched in low-pressure partial melts; differentiation of the earth can therefore lead to chemical stratification of the sort that results in quite different crystal structures and intrinsic densities in various layers. This crystal chemical effect can override differences in mean atomic weight. The mean atomic weight is a useful concept in a different context precisely for the reason that a variety of crystals with different intrinsic densities can have the same value.

The following is a simple but plausible scenario that leads to a chemically stratified rather than a homogeneous mantle. Suppose the upper mantle produced basaltic magmas while the earth was accreting. Alternatively, suppose the mantle was initially homogeneous and convecting but partial melting only occurred in the upper mantle. In either case, low-pressure differentiation rules would apply, and the end result would be a thick surface layer of basalt (Figure 1). If the earth differentiated as efficiently as the moon, it should have a basalt layer at least $200 \mathrm{~km}$ thick. This is clearly not the case today. As the earth cools, the lower part of this hypothetical basalt layer converts to eclogite, and eventually, the surface layer becomes unstable and sinks through the upper mantle. Although this is a hypothetical scenario, it would explain the absence of an early geological record. The present style of thin plate tectonics would not start until conditions allowed oceanic lithosphere to subduct without immediately encountering denser material or such high temperatures that it remelted. These conditions may include the requirement for phase stability of eclogite in the upper mantle, i.e., cold temperatures. The next question is, What happens to the sinking eclogite?

Copyright $\odot 1979$ by the American Geophysical Union.
To address this question, I have estimated the densities in the various phase assemblages of eclogite and 'normal' mantle. The eclogite is given the nominal density of $3.5 \mathrm{~g} /$ $\mathrm{cm}^{3}$, appropriate for about $12 \% \mathrm{FeO}$ and $17 \% \mathrm{Al}_{2} \mathrm{O}_{3}$ [Ito and Kennedy, 1971]. For the model peridotite I take $\mathrm{Mg}_{2} \mathrm{SiO}_{4} \cdot \mathrm{MgSiO}_{3}$. The phase boundaries and zero-pressure densities are estimated from results given by Liu [1977], Akaogi and Akimoto [1977], and Ito and Matsui [1977]. Figure 2 gives the results for the two assemblages. Note that eclogite is denser than $\mathrm{Al}_{2} \mathrm{O}_{3}$-poor mantle down to $670 \mathrm{~km}$ but, because of the broad stability field of garnet, it will be stopped by the ilmenite plus spinel transition.

The $\mathrm{Al}_{2} \mathrm{O}_{3}$-poor assemblage is free of both $\mathrm{Al}_{2} \mathrm{O}_{3}$ and $\mathrm{FeO}$, and therefore the densities given are lower bounds. Increasing the mean atomic weight of the right column to 21 increases the densities by about $0.2 \mathrm{~g} / \mathrm{cm}^{3}$, making normal $\mathrm{Al}_{2} \mathrm{O}_{3}$-poor mantle denser than 'eclogite' below about $500 \mathrm{~km}$.

These density estimates are for room temperature and pressure. It is difficult to estimate the in situ densities, but it is only the differential densities that count. The coefficient of thermal expansion of garnet is about $30 \%$ higher than that of spinel and of corundum; these are structural analogs of the mantle assemblages near $670 \mathrm{~km}$.

This would increase the density contrast between garnet solid solution (s.s.) and ilmenite plus spinel by $0.07 \mathrm{~g} / \mathrm{cm}^{3}$ at 2000 $\mathrm{K}$. The above assemblages differ by about $20 \%$ in bulk modulus, which is approximately the observed increase across the 670-km discontinuity. At 0.23 -mbar pressure this almost exactly cancels the density differential due to temperature. The

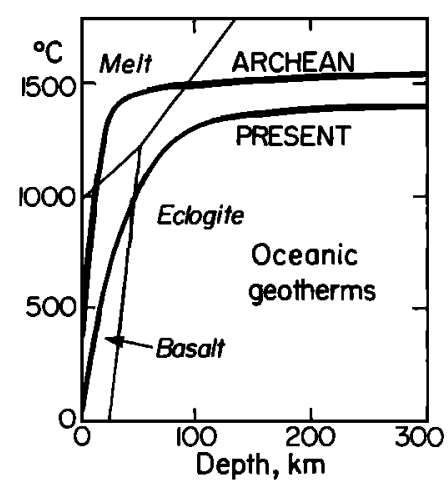

Fig. 1. Schematic representation of Archean and present oceanic geotherms [Davies, 1979] superposed on phase diagram of basalt-eclogite system [e.g., Wyllie, 1971]. A thick surface layer of basalt becomes gravitationally unstable when it cools into the eclogite phase stability field. 


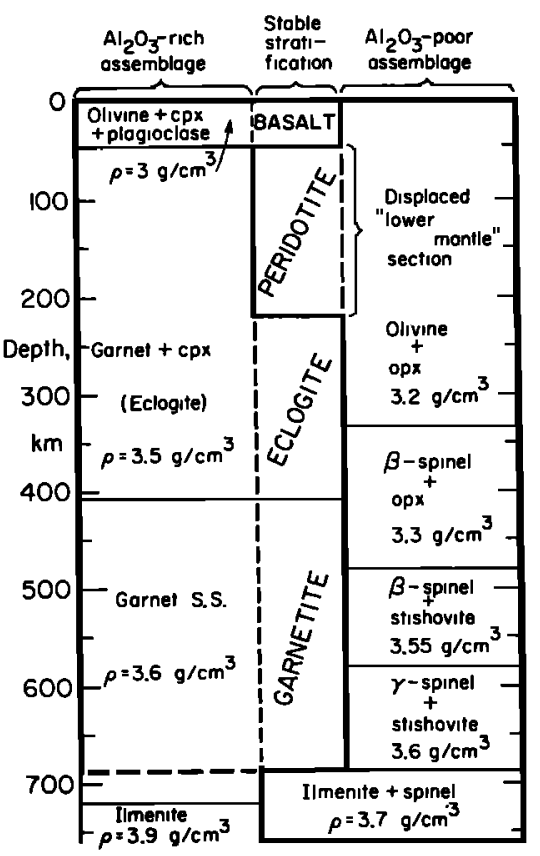

Fig. 2. Phase relations in $\mathrm{Al}_{2} \mathrm{O}_{3}$-rich system (garnet + clinopyroxene) and $\mathrm{Al}_{2} \mathrm{O}_{3}$-poor system (olivine + orthopyroxene) and the resulting density stratification (center column) in a mantle containing both peridotite and eclogite. Constructed from results of Liu [1977], Akaogi and Akimoto [1977], and Ito and Matsui [1977]. Densities are zeropressure values. The left column is computed with $\mathrm{FeO} \sim 12$ wt \% The right column is free of both $\mathrm{FeO}$ and $\mathrm{Al}_{2} \mathrm{O}_{3}$ and therefore gives minimum densities. Regardless of the details the transformations to dense phases such as ilmenite and perovskite occur at lower pressures in $\mathrm{Al}_{2} \mathrm{O}_{3}$-poor silicates. This would appear to prevent subduction of eclogite into the lower mantle. Eclogite displaces lower mantle at the 670-km discontinuity. The top of the eclogite layer is taken to be at the Lehmann discontinuity.

pressure increases the densities by about $0.4 \mathrm{~g} / \mathrm{cm}^{3}$, and the temperature decreases the densities by about $0.3 \mathrm{~g} / \mathrm{cm}^{3}$. The differential effects are only $20 \%$ as large, so conclusions based on densities at standard conditions are likely to be valid at in situ conditions.

Subducting eclogite may be appreciably colder than ambient mantle. Taking the volume coefficient of expansion of garnet [Clark, 1966], $22 \times 10^{6} /{ }^{\circ} \mathrm{C}$, and a temperature difference of $400^{\circ} \mathrm{C}$, the density difference is about $0.04 \mathrm{~g} / \mathrm{cm}^{3}$.

Ringwood [1975] and Ito and Matsui [1977] estimate that the zero-pressure density of normal mantle below $670 \mathrm{~km}$ will be about $3.9-4.0 \mathrm{~g} / \mathrm{cm}^{3}$, in agreement with our simple model mantle after allowance for the effect of FeO. Ringwood [1975] uses a higher-density eclogite and estimates the density of garnet s.s. to be $3.78 \mathrm{~g} / \mathrm{cm}^{3}$. This is still lower than any of the above estimates of normal mantle density below $670 \mathrm{~km}$. It seems likely therefore that eclogite will remain above $670 \mathrm{~km}$ and possibly $500 \mathrm{~km}$. The sharpness of the $670-\mathrm{km}$ discontinuity and the increase in earthquake activity near this depth suggest that this is the boundary that stops the sinking plates.

Transformation to dense deep mantle phases such as ilmenite and perovskite occur $30-60 \mathrm{~km}$ deeper for a mantle assemblage with $12 \% \mathrm{Al}_{2} \mathrm{O}_{3}$ (eclogite) than for one with $3 \%$ $\mathrm{Al}_{2} \mathrm{O}_{3}$ (peridotite). Liu [1977] estimated that ecologite is denser than peridotite to depths of about $570 \mathrm{~km}$ and then is less dense to about $750 \mathrm{~km}$. These crossover depths are controlled by phase changes whose transition pressures are difficult to estimate with current petrological data and which, in any event, are likely to have been deeper with Precambrian geotherms. We have demonstrated that a trapped eclogite layer is a plausible result of whole mantle convection and differentiation and that the original differentiation into eclogite and residual peridotite layers may have been irreversible. The reversible part of present-day plate tectonics may be simply the transfer of material into and out of the eclogite layer. We suggest that radial motion of material between layers requires partial melting (for example, basalt differentiation) or phase changes (for example, basalt-eclogite). The transformed material rises or sinks until it finds its own level.

Anderson [1979] discussed the possibility that the region of the mantle between the Lehmann $(220 \mathrm{~km})$ and $670-\mathrm{km}$ discontinuities is eclogite rather than peridotite. Surprisingly, an eclogite mineralogy with its attendant implications regarding seismic velocities, heat flow, trace elements, and overall chemistry of the earth cannot be ruled out. An upper mantle eclogite layer, whether produced by early basaltic differentiation and overturn, eclogite fractionation, or subsequent subduction, will likely remain in the upper mantle. The mantle may therefore be chemically stratified and stable against whole mantle or even whole upper mantle convection. Material can leave this layer only if it partially melts during the course of its convective overturns. The source of oceanic basalts would be diapirs from the eclogite layer. Material is returned to the layer by subduction. The large density contrasts between basalt and eclogite and the intervening peridotite layer would make the interchange rapid.

Acknowledgments. The author acknowledges helpful discussions with Leon Silver and Frank Richter. This research was supported by NASA contract NGL05-002-069. Contribution 3240, Division of Geological and Planetary Sciences, California Institute of Technology, Pasadena, California 91125.

\section{REFERENCES}

Akaogi, M., and S. Akimoto, Pyroxene-garnet solid solution, Phys. Earth Planet. Interiors, 15, 90-106, 1977.

Anderson, D. L., The upper mantle transition region: Eclogite?, Geophys. Res. Lett., 6, 433, 1979.

Clark, S. P., Jr. (Ed.), Handbook of Physical Constants, Geol. Soc. Amer. Mem., 97, 587 pp., 1966.

Davies, G. F., Whole mantle convection and plate tectonics, Geophys. J. Roy. Astron. Soc., 49, 459-486, 1977.

Davies, G. F., Thickness and thermal structure of continental crust and root zones, in press, 1979.

Elsasser, W. M., P. Olson, and B. D. Marsh, The depth of mantle convection, J. Geophys. Res., 84, 147-155, 1979.

Ito, K., and G. C. Kennedy, An experimental study of the basalt garnet granulite-eclogite transition, in The Structure and Physical Properties of the Earth's Crust, Geophys. Monogr. Ser., vol. 14, pp. 303314, AGU, Washington, D. C., 1971.

Ito, E., and $\mathbf{Y}$. Matsui, Silicate ilmenites and the post-spinel transformations, in High Pressure Research, edited by M. Manghnani and S. Akimoto, pp. 193-208, Academic, New York, 1977.

Liu, L. G., The system enstatite-pyrope at high pressures and temperatures and the mineralogy of the Earth's mantle, Earth Planet. Sci. Lett., 36, 237-243, 1977.

Ringwood, A. E., Composition and Petrology of the Earth's Mantle, 618 pp., McGraw-Hill, New York, 1975.

Wyllie, P. J., The Dynamic Earth, 416 pp., John Wiley, New York, 1971.

(Received April 12, 1979;

revised June 4, 1979;

accepted June 18, 1979.) 